Dr Alyson Parris, School of Biological Sciences, University of East Anglia, Norwich Research Park, Norwich, Norfolk, NR47TJ, UK

Dr Mark Williams, School of Biological Sciences, University of East Anglia, Norwich Research Park, Norwich, Norfolk, NR47TJ, UK

Correspondence to:

Dr Mark R Williams, School of

Biological Sciences, University of East Anglia, Norwich

Research Park, Norwich, Norfolk NR47TJ, UK;

m.r.williams@uea.ac.uk 
Human Colonic Crypt Culture

\title{
A human colonic crypt culture system to study regulation of stem cell-driven tissue renewal and physiological function
}

\begin{abstract}
The intestinal epithelium is one of the most rapidly renewing tissues in the human body and fulfils vital physiological roles such as barrier function and transport of nutrients and fluid. Investigation of gut epithelial physiology in health and disease has been hampered by the lack of ex vivo models of the native human intestinal epithelium. Recently, remarkable progress has been made in defining intestinal stem cells and in generating intestinal organoid cultures. In parallel, we have developed a 3D culture system of the native human colonic epithelium that recapitulates the topological hierarchy of stem cell-driven tissue renewal and permits the physiological study of native polarised epithelial cells. Here we describe methods to establish 3D cultures of intact human colonic crypts and conduct real-time imaging of intestinal tissue renewal, cellular signalling and physiological function, in conjunction with manipulation of gene expression by lentiviral or adenoviral transduction. Visualisation of mRNA- and protein-expression patterns in cultured human colonic crypts, and crossvalidation with crypts derived from fixed mucosal biopsies, is also described. Alongside studies using intestinal organoids, the near-native human colonic crypt culture model will help to bridge the gap that exists between investigation of colon cancer cell lines and/or animal (tissue) studies, and progression to clinical trials. To this end, the near native human colonic crypt model provides a platform to aid the development of novel strategies for the prevention of inflammatory bowel disease and cancer.
\end{abstract}


Key Words: human, intestine, colon, crypt, stem cells, culture, signalling, immunocytochemistry, in situ hybridisation, imaging, proliferation, migration, tissue renewal.

\section{Introduction}

The human large intestinal epithelium is a monolayer of polarised epithelial cells that is exquisitely organised into millions of blind-ending flask-like invaginations called colonic crypts (Fig. 1). In the absence of villi (i.e. finger-like protrusions found in the small intestine), each colonic crypt is linked to its neighbour by adjoining surface epithelial cells that surround the crypt opening. Approximately 10 billion cells are shed from the gut surface epithelium each day. These are continuously replaced by intestinal stem cell progeny that emerge from a population of proliferating LGR5/OLFM4-positive stem cells located at the base of each colonic crypt[1]. Stem cell progeny (i.e. transit amplifying cells) proliferate, migrate and differentiate (into absorptive enterocytes, mucus-secreting goblet cells, hormone-secreting enteroendocrine cells and tuft cells that secrete prostaglandins and opioids) along the cryptaxis before they are shed from the surface epithelium. The prevailing dogma is that a hierarchy of rapid tissue renewal (approx. 5-7 days) minimises the life-long accumulation of molecular damage and disease risk[2]. Long-lived stem cells are positioned in a relatively safe harbour (e.g. sterile) at the crypt-base, from where they fuel the constant replenishment of short-lived progeny that migrate up the crypt-axis and differentiate before being shed into the gut lumen within a matter of days. Each crypt houses all of the secretory and absorptive cell types that contribute to regular flushing of the crypt lumen (with fluid and mucus secretions) and maintenance of barrier function. As such, individual crypts not only represent the self-renewing unit of the tissue, but also fulfil the physiological functions of the intestinal epithelium. 
Isolation of intact colonic crypts has long-held the promise that functional self-renewing units of the human intestinal epithelium (i.e. crypts) could be studied ex vivo in real-time when placed in $3 \mathrm{D}$ culture conditions. Intact colonic crypts can be readily isolated following disaggregation of the lamina propria extracellular matrix by chelation of divalent cations or enzymatic treatment $[3,4]$. However, in this configuration, devoid of physical cell-matrix interactions, isolated crypts are prone to anoikis[5]. Rescue of isolated crypt viability by embedding live crypts in a collagen matrix to restore cell-matrix interactions was an important first step towards reconstituting a viable self-renewing crypt culture system[3,6]. Although we and others demonstrated that embedding colonic crypts in a collagen gel maintained crypt morphology, cell polarity and physiological function for a few days[3,7], sustained cultured crypt viability required activation of mitogenic signals in combination with suppression of anti-proliferative signalling pathways. The Clevers' Laboratory paved the way by capitalising on their seminal work on Wnt signalling, intestinal stem cells and cancer[8-10], and developed the mouse small intestinal organoid culture system[11,12]. This 'mini-gut' culture system formed the basis for the development of human organoid cultures from the intestinal epithelium[13,14,1] and from (inducible) pluripotent stem cells[15], both of which hold the potential for therapeutic transplantation[16,17]. For the study of native intact human colonic crypts, we adopted a similar approach whereby crypts are embedded in a basement membrane-derived matrix, Matrigel[18], instead of collagen I[7], and serum-free culture medium is supplemented with the intestinotrophic factors IGF-1 (activator of RAS signalling pathway) and R-spondin (activator of Wnt signals) in combination with inhibitors of BMP (Noggin or Gremlin proteins) and TGF $\beta$ (SB431542 or A83-01 small molecules) signalling pathways[18]. The established human colonic crypt culture system provides a 
near-native model of a self-renewing tissue unit whereby epithelial cell polarity, tissue topology and the hierarchy of stem cell-driven tissue renewal are maintained.

Two major hall marks of intestinal crypts that are desirable to recapitulate in culture are: (i) the hierarchy of crypt cell renewal along the topological axis of the tissue and (ii) functional epithelial cell polarity. Spatial correlation of protein/gene expression patterns with these characteristics can give valuable clues about gene function. Comparison of expression patterns in human cultured crypts should be made withcrypts derived from immediately fixed colorectal tissue samples for cross-validation of the near-native culture system. Development of a validated near-native colonic crypt culture system ex vivo provides the opportunity to gain insights into the regulation of (patho)physiological function. For example, assessment of signalling pathway status in immediately fixed clinical human colorectal tissue samples, together with assessment of the effects of pathway activation/inhibition on the processes of crypt (stem) cell proliferation, migration and shedding in cultured crypts, demonstrated that activation of canonical Wnt signals in combination with suppressed TGF $\beta / \mathrm{BMP}$ pathways promotes renewal of the native human colonic epithelium[18,19]. Similarly, comparison of polarised expression patterns for NKCC1 in immediately fixed clinical human colorectal tissue samples with near-native cultured human colonic crypts proved invaluable when studying the functional regulation of fluid secretion by calcium-dependent internalisation of NKCC1 in native polarised colonic crypt cells[7]. These studies required adaptation of standard methods for manipulation of gene expression and assays for signalling pathway activation, cell proliferation, migration and shedding so that they may be applied to the 3D human colonic crypt culture system.

The aim of this chapter is to provide protocols not only for human colonic crypt isolation and culture, but also for the application of a range of techniques that we have found invaluable to 
date. For example, a significant amount of time has been invested in optimising the conditions for immunocytochemistry, mRNA in situ hybridisation, and brightfield timelapse and fluorescence real-time imaging. These techniques translate into methodologies to assess labelling of markers for intestinal stem cells (e.g. LGR5/ OLFM4), goblet cells (e.g. muc2), absorptive enterocytes (e.g. FABP1), tuft cells (e.g. COX1, COX2), enteroendcrine cells (e.g. chromogranin A, serotonin), cell signalling pathway status (e.g. beta catenin; phospho-smad 1,5,8; calcium waves), protein trafficking (e.g. NKCC1 internalisation), crypt cell proliferation (e.g. BrDU, Ki67), crypt cell migration (timelapse imaging) and crypt cell shedding (timelapse imaging)[7,18].

\section{Materials}

1. Human colonic crypt isolation

1. Dissecting scissors, tissue forceps and knives (25mm blades, Roboz RS-6270)

2. $25 \mathrm{ml}$ (Universal) screw top plastic bottles (RL Slaughter, UK)

3. Crypt isolation buffer: $\mathrm{NaCl} 140 \mathrm{mM}, \mathrm{KCl} 5 \mathrm{mM}$, Hepes (N-2hydroxyethylpiperazine-N2-ethanesulphonic acid) $10 \mathrm{mM}$, d-glucose $5.5 \mathrm{mM}, \mathrm{Na}_{2} \mathrm{HPO}_{4}$ 1, EDTA (diaminoethanetetraacetic acid disodium salt) $10 \mathrm{mM}$, dithiothrietol $(1 \mathrm{mM})$, bovine serum albumin $(0.1 \% \mathrm{w} / \mathrm{v})$. (All from Sigma, UK)

4. $25 \mathrm{ml}$ Universal plastic bottle filled with $20 \mathrm{ml}$ AdF12/DMEM culture medium (Invitrogen)

2. Adenoviral and lentiviral transduction [Optional]

1. Hexadimetherine bromide (\#H9268, Sigma, UK; 8 mg/ml stock) 
2. Adenovirus or lentivirus particles containing, for example, a gene reporter (e.g. Wnt reporter, HIV-based, VSV-G; SABiosciences) or dominant negative mutant (e.g. adenoviral CMV-DN-TCF4; type 5, dE1E3; Vector Biolabs).

3. Human colonic crypt culture

1. Matrigel $400 \mu \mathrm{l}$ aliquot (Becton Dickinson, UK; \#BD354230)

2. AdF12/DMEM culture medium (Invitrogen, UK; \#12634-028)

3. Penicillin/Streptomycin (x10000/10000 U/ml; Invitrogen \#15140122)

4. Glutamine (x100; Invitrogen; \#25030-081)

5. B27 growth supplement (\#12587-010, Invitrogen, UK)

6. N2 growth supplement (\#17502-048, Invitrogen, UK)

7. N-acetylcysteine (0.5M stock in PBS, Sigma; \#A9165-5G )

8. Hepes (Invitrogen, \#15630-056)

9. A83-01 (25 mM stock in DMSO; Tocris, UK; \#2939)

10. Human recombinant R-spondin $(250 \mu \mathrm{g} / \mathrm{ml}$ stock in $0.1 \%$ BSA/PBS; Sino Biological, China or R\&D Systems, UK)

11. Human recombinant Wnt $3 \mathrm{~A}(100 \mu \mathrm{g} / \mathrm{ml}$ stock in $0.1 \%$ BSA/PBS; R\&D Systems)

12. Human recombinant Noggin $(200 \mu \mathrm{g} / \mathrm{ml}$ stock in $0.1 \%$ BSA/PBS; Peprotech, UK)

13. Human recombinant IGF-1 $(100 \mu \mathrm{g} / \mathrm{ml}$ stock in $0.1 \%$ BSA/PBS; Sigma, UK)

14. Prostaglandin E2 (1 mM stock in DMSO; Caymen Chemicals) 
15. Formulate $15 \mathrm{mls}$ of human colonic crypt growth medium; 15 mls AdF12/DMEM, $10 \mu \mathrm{M}$ hepes, $0.5 \mu \mathrm{M}$ A83-01, 100 nM PGE 2,1 mM n-acetylcysteine, $200 \mathrm{ng} / \mathrm{ml}$ human recombinant Noggin, 100 $\mathrm{ng} / \mathrm{ml}$ human recombinant Wnt 3A, $500 \mathrm{ng} / \mathrm{ml}$ human recombinant Rspondin-1, $50 \mathrm{ng} / \mathrm{ml}$ human recombinant IGF-1.

16. $4 \times 12$ well cell culture plates (Nunc multidish, or Corning) or glass bottomed multiwall dish (Mat tek) for timelapse or fluorescence imaging (3.1.4)

17. Borosilicate glass, zero thickness, $16 \mathrm{~mm}$ diameter coverslip (VWR 631-0151), autoclaved.

4. Bright field and fluorescence time-lapse imaging

1. Live cell imaging system including climate control for temperature and $\mathrm{CO}_{2}$, automated stage, inverted microscope, range of objective lenses, bright field DIC optics and fluorescence light source with range of excitation and emission filters. We use both Zeiss-Axiovision and Nikon-NIS elements based systems for timelapse imaging and a Photon Technology Image Ratio Pro system based on a Nikon inverted microscope for calcium imaging

2. Glass bottom mutliwell plate (e.g. Mat Tek) or POC chamber (PeCon, Germany)

3. Hepes-buffered saline (HBS): $\mathrm{NaCl} 140 \mathrm{mM}, \mathrm{KCl} 5 \mathrm{mM}$, Hepes (N-2-hydroxyethylpiperazine-N2-ethanesulphonic acid) $10 \mathrm{mM}$, D-glucose $5.5 \mathrm{mM}, \mathrm{Na}_{2} \mathrm{HPO}_{4} 1 \mathrm{mM}, \mathrm{CaCl}_{2} 1 \mathrm{mM}$, $\mathrm{MgCl}_{2} 0.5 \mathrm{mM}$. 
4. Fluorescence probes: e.g. Fura2 (calcium-sensitive dye, $1 \mathrm{mM}$ stock DMSO; Invitrogen), calcein-AM (viable cell dye, $5 \mathrm{mM}$ stock, Invitrogen) and propidium iodide (dead cell label, $1 \mathrm{mg} / \mathrm{ml}$ stock, Invitrogen).

5. Immunocytochemistry and confocal microscopy

For 20 coverslips, each with crypts cultured in a polymerised droplet of Matrigel, the following will be needed:

1. Phosphate buffered saline solution (PBS) (100 ml) prepared from dissolving 1 tablet (Oxoid BR0014G) per $100 \mathrm{ml} \mathrm{de-}$ ionised water in a re-useable glass bottle. Autoclave before use.

2. Paraformaldehyde, $4 \%$ (PFA) $(10 \mathrm{ml})$ in PBS, made by adding $4 \mathrm{~g}$ of PFA powder (Sigma P6148) per $100 \mathrm{ml}$ of previously autoclaved PBS or DEPC treated PBS, gently stirred whilst warming on a hotplate (covered, in a fume hood) so that the temperature never exceeds $65^{\circ} \mathrm{C}$ until the solution is clear (1-4 h). It is cooled to $4^{\circ} \mathrm{C}, \mathrm{pH}$ adjusted to 7.4 with $4 \mathrm{M} \mathrm{NaOH}$, and aliquotted into $7 \mathrm{ml}$ plastic screw top single use bottles ("Bijoux" E1412-0711 Starlab) or similar $25 \mathrm{ml}$ bottles ("Universal", $25 \mathrm{ml}, \mathrm{R} \& \mathrm{D}$ Slaughter code U128) and stored for up to 1 month in a $-80^{\circ} \mathrm{C}$ freezer, thawed only immediately before use.

3. TritonX solution, $0.5 \%$ (Roche) $(10 \mathrm{ml})$ in PBS prepared immediately before use (Caution:light-sensitive).

4. Ammonium chloride, $100 \mathrm{mM} \mathrm{NH}_{4} \mathrm{Cl}_{2}$ (Sigma A9434) (10ml) solution in PBS. 
5. Optional antigen retrieval solution of Sodium dodecyl sulphate (SDS, Melford B2008) (5 ml) which is only sparingly soluble in aqueous solutions. It is best prepared at least $24 \mathrm{~h}$ in advance by adding $1 \%$ powder to PBS in a glass bottle and left on a rocker overnight until all has dissolved. It will store for 1 month at RT. Alternative antigen retrieval solutions such as $1 \mathrm{M} \mathrm{HCl}$ in PBS (5 ml) or citrate buffer (10 mM tri-sodium citrate (Sigma W302600) in water adjusted to $\mathrm{pH} 6$ by addition of $\mathrm{HCl})(100$ ml) may be required as specified by antibody suppliers.

6. Blocking solution $(5 \mathrm{ml})$ prepared up to $1 \mathrm{~h}$ before use by addition of $1 \%$ Bovine serum albumin (BSA) (Sigma A2153) to PBS. Optional 10\% normal donkey serum (Sigma 9663) and/or 10\% normal goat serum (Abcam Ab7481) can be added, depending on the species of secondary antibody to be used.

7. Coverslip mounting media $(200 \mu \mathrm{l})$ to prevent photo-bleaching (containing nuclear counterstain if required, e.g. propidium iodide or DAPI) such as Vectashield ${ }^{\mathrm{TM}}$ (Vector labs H1000, H1200 or H1300), coated microscope slides (10) (Polysine ${ }^{\mathrm{TM}}$ VWR), and plain varnish $(0.5 \mathrm{ml})$ (eg. clear nail varnish) to seal around edges of coverslips.

8. Primary antibodies (1-10 $\mu \mathrm{l})$ suitable for immunofluorescence, fluorophore conjugated secondary antibodies (0.5-5 $\mu 1)$.

6. mRNA in situ hybridisation

1.For 20 coverslips the following are required 
2.DEPC water or DEPC PBS are used throughout and are made by adding $0.1 \%$ ( $1 \mu 1$ per $\mathrm{ml}$ ) diethylpyrocarbonate (DEPC, sigma) to water (or PBS solution) and left uncovered overnight at room temperature (in a fume hood). Next day, cover and autoclave solutions to remove the DEPC.

3. Hybridisation buffer is prepared with $25 \mathrm{ml}$ Formamide, $3.25 \mathrm{ml} \times 20$ SSC pH5, $2.5 \mathrm{ml}$ Chaps (10\% or $1 \mathrm{~g} / 10 \mathrm{ml}), 1 \mathrm{ml}$ Tween-20 (10\%), 0.5 ml 0.5 M EDTA pH8, 100 $\mu 1$ Heparin* (50 mg/ml), $125 \mu 1$ tRNA ${ }^{\&}$ (from yeast, $20 \mathrm{mg} / \mathrm{ml}$ ), make up to $50 \mathrm{ml}$ with DEPC water and store at $-20^{\circ} \mathrm{C}$, only remove from freezer immediately before required. Use within 1 month. *Heparin sodium salt from porcine intestinal mucosa SIGMA H3149\& Yeast type III RNA s.cervisae SIGMA R6750.

4.Salmon sperm DNA (SS DNA,Sigma D7656) is denatured by immersing a $1.7 \mathrm{ml}$ flip top centrifugation tube with the lid covered with parafilm containing a small volume $(75 \mu 1)$ SS DNA in a vacuum flask containing water heated to $95^{\circ} \mathrm{C}$ for 5 minutes. The tube is removed and allowed to cool (2 minutes) before hybridisation buffer and an appropriate concentration of probe is added,(see Note 11 ) and pre -warmed for at least $1 \mathrm{~h}$ at the incubation temperature to be used for hybridisation reaction, (Hybridisation mix).

5.PBST (30 ml ), $0.1 \%$ Tween-20 in DEPC treated PBS $(0.5 \mathrm{ml} 10 \%$ Tween-20 per $500 \mathrm{ml}$ of PBS)

6.PBST:MeOH (5 ml), a 50:50 mix of PBST and methanol 7.HCl-PBST (5 ml), 1M HCl in PBST 
8.Make up a fresh stock of Proteinase K (BDH 390923P) in a flip top tube by adding $0.005 \mathrm{~g}$ PK to $0.5 \mathrm{ml}$ DEPC- PBS. From this stock add $1 \mu \mathrm{l} / \mathrm{ml}$ to DEPC-PBS to make $5 \mathrm{ml}$ Proteinase $\mathrm{K}$ working solution. 9.Hybridisation humidity buffer( $20 \mathrm{ml})$, formamide and $10 \%$ x $20 \mathrm{SSC}$ $(\mathrm{pH} 5)$

10. $\mathrm{x} 20 \mathrm{SSC}, 175.3 \mathrm{~g} \mathrm{NaCl}+88.2 \mathrm{~g}$ Sodium Citrate in $800 \mathrm{ml}$ DEPC water $\mathrm{pH}$ adjusted ( $\mathrm{pH} 7$ with $10 \mathrm{~N} \mathrm{NaOH}$, or $\mathrm{pH} 51 \mathrm{M}$ citric acid). Make up volume to 1 litre, dispense into aliquots and sterilise by autoclaving. This stock concentrate can be used to make intermediate dilutions such as $5 \mathrm{ml} \times 5 \mathrm{SSC}(\mathrm{pH} 5)$ or $5 \mathrm{ml}$ x0.2 SSC ( $\mathrm{pH}$ 5) by dilution with DEPC water.

7. Double immunocytochemistry and in situ hybridisation

1.Post-hybridisation blocking solution ( $5 \mathrm{ml}), 2 \%$ BBR blocking reagent (Roche 11096176001), 20\% normal donkey serum (Sigma D9663) in Tris buffered saline (TBS).

2.TBS (10 ml), $50 \mathrm{mM}$ Tris-Cl, $\mathrm{pH} 7.5150 \mathrm{mM} \mathrm{NaCl}$, dissolve $6.05 \mathrm{~g}$ Tris and $8.76 \mathrm{~g} \mathrm{NaCl}$ in $800 \mathrm{~mL}$ of DEPC $\mathrm{H}_{2} \mathrm{O}$. Adjust $\mathrm{pH}$ to 7.5 with $1 \mathrm{M} \mathrm{HCl}$ and make volume up to $1 \mathrm{~L}$ with DEPC $\mathrm{H}_{2} \mathrm{O}$.

3.Normal human serum $(40 \mu 1)$.

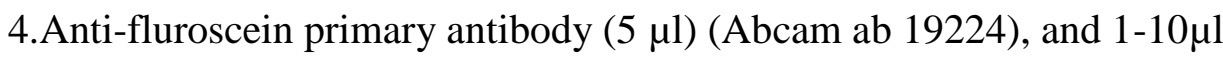
other primary and secondary antibodies suitable for immunofluorescence labelling.

5.Ten coated microscope slides (Polysine ${ }^{\mathrm{TM}}$, VWR), $200 \mu 1$ mounting media (Vectashield) and sealing varnish $(1 \mathrm{ml})$.

8. Cross-validation with immediately fixed microdissected (MD) crypts 
Equipment as follows:

Dissecting microscope with light source (Zeiss Discovery v1.2

microscope, KL2500 light source, flexible light guide with twin spot illuminators).,

Dissecting stage made from $10 \mathrm{~cm}$ disposable petri dish with dark card inside and edges sealed with tape

2 micro-dissecting knives with $25 \mathrm{~cm}$ blades (2.1.1)

Biopsies or surgically obtained mucosal strips as described in crypt isolation are fixed immediately on removal from the patient in PFA (4\% in PBS) at $4^{\circ} \mathrm{C}$ for 1 hour. The fixed tissue is removed from the PFA and left in PBS to wash overnight at $4^{\circ} \mathrm{C}$. If tissue is to be used for in-situ it is fixed and processed in solutions treated with DEPC and used within 24 h. For protein localisation tissue can be stored in fridge for up to 7 days. (see Note 18)

For 20 coverslips

1.Small piece of fixed, washed, mucosal tissue

2.Micro-dissection solution $(25 \mathrm{ml}) 1 \mathrm{mM} \mathrm{CaCl}_{2}$ in $\mathrm{PBS}$.

3.Hydrophobic barrier pen (e.g. Vector H4000)

4.TritonX $0.5 \%$ in PBS $(5 \mathrm{ml})$

5. PBS (10 ml)

6. Matrigel ${ }^{\mathrm{TM}}$ thawed on ice $(2 \mathrm{x} 100 \mu \mathrm{l})$

7.Two 12 well culture plates each with 10 coverslips as described in crypt isolation materials, pre warmed in $37^{\circ} \mathrm{C}$ incubator. 
8.Two plain glass microscope slides $(75 \mathrm{~mm} \times 25 \times 1.5)$ and two $7 \mathrm{ml}$ bijoux bottles.

\section{Methods}

\subsection{Human colonic crypt isolation}

1. Collect a $9 \mathrm{~cm}^{2}$ (i.e. $3 \mathrm{~cm} \mathrm{x} 3 \mathrm{~cm}$ ) piece of mucosa from colorectal surgery and cut into $0.5 \mathrm{~cm}$ square pieces, or collect $5 \mathrm{x}$ biospy samples from endoscopy (see Note 1).

2. Remove residual muscularis mucosa with dissecting scissors and forceps and discard.

3. Wash mucosal tissue samples with crypt isolation solution (2.1.3) and place in a $20 \mathrm{ml}$ volume contained in a Universal plastic bottle (2.1.2). Incubate at room temperature for 90 mins (see Note 2).

4. Meantime, fill $5 \times$ Universal plastic bottles (2.1.2) with $10 \mathrm{ml}$ of crypt isolation solution (2.1.3).

5. At the end of the 90 min. incubation period (3.1.4), place $5 \mathrm{x}$ tissue biopsy samples obtained at endoscopy, or $5 \times 0.5 \mathrm{~cm}$ square pieces of colorectal mucosa derived from surgery (3.1.2), into a Universal bottle pre-filled with 10 mls of crypt isolation solution (3.1.5). Shake the solution vigorously to liberate whole, intact, isolated crypts (See Notes $3 \& 4$ ). Liberated crypts will sediment under gravity to the bottom of the canonical insert of the Universal plastic bottle (See Notes 5 and 6).

6. Carefully remove the remainder of the mucosal tissue samples from the first Universal plastic bottle (3.1.6) and transfer them into the second of five Universals that have been pre-filled with crypt isolation solution (3.1.5). 
7. Repeat the process of vigorous shaking, crypt liberation, and sedimentation (3.16-3.17) for the remaining four Universal bottles that have been pre-filled with crypt isolation solution.

8. At this stage you will have $5 \mathrm{x}$ Universal plastic bottles each with a pellet of isolated crypts at the bottom of the canonical insert. Collect each pellet of crypts with a $200 \mu$ l pipette and tip and place into a single Universal plastic bottle filled with $20 \mathrm{ml}$ of ice-cold AdF12/DMEM (2.1.4). Crypts will sediment under gravity and form a pellet (see Note 6).

9. Repeat steps 3.1.6-3.1.10 until crypts cease to be liberated from mucosal tissue samples

10. Remove AdF12/DMEM supernatant from accumulated pellet of isolated crypts (3.1.9) and adjust volume of residual crypt suspension to a density of 500 crypts/100 $\mu \mathrm{l}$ AdF12/DMEM

\subsection{Adenoviral and lentiviral transduction [optional]}

1. Incubate isolated crypt suspension (3.1.11) on ice for 15 minutes with hexadimetherine $(8 \mu \mathrm{g} / \mathrm{ml})$ and the desired adenovirus or lentivirus vector (e.g. 2.2) at a multiplicity of infection of $250 \times 10^{3} \mathrm{TU} / \mathrm{crypt}$.

3.3. Human colonic crypt culture

1. Prepare $15 \mathrm{mls}$ of human colonic crypt growth medium in advance of the isolation (2.3.15).

2. Thaw a $400 \mu \mathrm{l}$ frozen aliquot of Matrigel on ice for 30 mins (2.3.1).

3. Add $1 \mathrm{ml}$ of PBS to the corner wells of each 12 well plate (2.3.12) and add one glass coverslip (2.2.13) to the remaining 8 wells of each 12-well plate. Prewarm 12 well plates at $37^{\circ} \mathrm{C}$ for 30 mins (see Note 8). 
4. Take $100 \mu \mathrm{l}$ of isolated crypt suspension (2.1.11) and add to thawed $400 \mu \mathrm{l}$ aliquot of Matrigel on ice and mix carefully.

5. Dispense $20 \mu \mathrm{l}$ of isolated crypt/Matrigel suspension (3.3.3) on to each coverslip and return $4 \times 12$ well plates to $37^{\circ} \mathrm{C}$ incubator for $15 \mathrm{~min}$. until Matrigel has polymerised.

6. Remove from incubator and flood polymerised Matrigel/crypt droplet with 400 $\mu \mathrm{l}$ of human colonic crypt culture medium; return to incubator

7. Change culture medium every other day. A typical field of view and appearance of crypt morphology following 7 days in culture is shown in Fig. 2.

8. Matrigel will destabilise progressively in colonic crypt culture. Cultured crypts will need re-plating into a fresh Matrigel droplet every week. Crypts can be liberated by incubation in crypt isolation buffer (2.1.3) for 20 mins on ice followed by mechanical agitation with a $1 \mathrm{ml}$ pipette and tip. Liberated crypts should be collected by sedimentation in AdF12/DMEM and re-suspended into fresh Matrigel as above (see Note 9)

\subsection{Real-time bright field and fluorescence imaging}

1. Mount single glass coverslips into POC chamber or use crypts that have been seeded onto a multiwell plate with glass bottom (2.4.2).

2. To monitor crypt cell morphology, proliferation and migration in realtime, place multiwell plate into climate controlled chamber $\left(5 \% \mathrm{CO}_{2}\right.$, $37^{\circ} \mathrm{C}$ ) located on stage of inverted microscope and establish DIC illumination with a $\mathrm{x} 20$ objective (Note 10) 
3. Crypt cell proliferation, migration and shedding along the crypt-axis are optimally observed by taking an image every 5 minutes for the duration of the experiment[18] (see Fig. 3 for an example of crypt cell proliferation)

4. To monitor crypt cell volume[7] or viability[18], load crypts with calceinAM $(5 \mu \mathrm{M})$ for one hour, wash twice with HBS (2.4.3). Excite at $488 \mathrm{~nm}$ and visualise emission at $520 \mathrm{~nm}$.

5. To monitor crypt cell viability, incubate crypts with propidium iodide (1 $\mu \mathrm{g} / \mathrm{ml}$ ) which will fluoresce when it binds to the nuclei of cells that have lost the plasma membrane integrity. Excite propidium iodide at $488 \mathrm{~nm}$ and visualise emission at $620 \mathrm{~nm}$. Fig. 4 illustrates the live/dead (i.e. calcein/propidium iodide) labelling pattern of a human colonic crypt[18].

6. To monitor intracellular calcium signals, load crypts with Fura2-AM (5 $\mu \mathrm{M})$ for one hour. Wash crypts with HBS and excite alternately with 340 $\mathrm{nm}$ and $380 \mathrm{~nm}$. Intracellular calcium signals are visualised by monitoring the ratio of fluorescence emitted at $510 \mathrm{~nm}$ following excitation by $340 \mathrm{~nm}$ and $380 \mathrm{~nm}$. Fig. 5 illustrates a calcium signal invoked in the stem cell niche at the crypt base by stimulation of muscarinic acetylcholine receptors[7].

\subsection{Immunocytochemistry}

1. Select isolated, cultured crypts (in Matrigel affixed to glass coverslips) and if required stimulate with agonists or inhibitors and/or incubate with $\mathrm{BrDU}$ (10 $\mu \mathrm{M})$. Alternatively prepare MD crypts (3.8). Leave coverslips in the culture dish.

2. Aspirate off any culture medium and add sufficient 4\%PFA in PBS to cover each Matrigel $(200 \mu l)$. 
3. Aspirate off fixative, pipette on sufficient PBS to cover Matrigel as a wash, remove by aspirating and repeat.

4. Permeabalise crypts by covering in TritonX solution (omit for MD). Leave for 30 minutes.

5. Remove TritonX and wash twice in PBS (as 3 above).

6. Reduce cross linking of protein by adding ammonium chloride $\left(\mathrm{NH}_{4} \mathrm{Cl}_{2}\right)$ solution for 13 minutes.

7. Remove ammonium chloride and wash twice in PBS (as 3 above).

8. An optional step can be included here to improve epitope retrieval by addition of SDS solution, $1 \mathrm{M} \mathrm{HCl}$ solution (BrdU antigen), or by boiling the coverslips in citrate buffer for 5-10 minutes, as appropriate to the primary antibody to be used.

9. Wash twice in PBS if antigen retrieval step used.

10. Discourage non-specific antigen binding by blocking with $1 \%$ BSA solution (with optional 10\% normal goat and/or donkey serum) for $2 \mathrm{~h}$.

11. Prepare primary antibodies by diluting according to suppliers instructions (range 1:25 to 1:500 usually) in PBS.

12. Remove block by aspirating but do not wash, add $20 \mu \mathrm{l}$ of antibody per coverslip. Wrap culture dish in film to reduce evaporation loss and leave on for $12-24 \mathrm{~h}$.

13. Prepare (flurophore-conjugated) secondary antibody according to suppliers instructions (usually at half the concentration that the primary was used at) in PBS. 
14. Remove primary antibody by adding $200 \mu 1$ per coverslip of PBS and then aspirating off. Wash second time in PBS, remove and add $20 \mu \mathrm{l}$ per coverslip of secondary antibody mix.

15. Leave secondary antibodies on for $2 \mathrm{~h}$, preventing dish from exposure to ambient or artificial light by covering with foil or light-proof plastic box to avoid bleaching of flurophore.

16. Remove secondary antibodies as in 13 above, leave in PBS wash for $1 \mathrm{~h}$.

17. Lift out coverslips from dish, clean back surface with ethanol on a tissue add a drop of mounting media and invert the coverslip onto a coated microscope slide. Seal around edges of coverslip with a transparent varnish and store in a light proof box prior to imaging by confocal microscopy (see Fig. 6).

3.6. mRNA in situ hybridisation

1. For 20 coverslips cultured or MD crypts

2. Fix crypts on coverslips for 30 minutes in PFA (200uL per well) leaving them in the 12 well culture dish (see Note 12).

3. Whilst fixing prepare and pre-warm hybridisation mix in hybridisation oven

4. Aspirate off fixative and re-cover the crypts with PBST to wash. Remove, repeat wash.

5. Add PBST-MeOH so that each coverslip is covered for no more than 30 seconds, aspirate off, immediately replace with HCl-PBST (without wash), and leave on for 5 minutes.

6. Remove HCl-PBST and wash twice.

7. Add Proteinase-K solution for 10 minutes, remove and replace with PFA for 10 minutes. 
8. Remove fixative and wash twice. Remove as much of PBST as possible with aspirator and then leave coverslips uncovered to dehydrate on bench for $1 \mathrm{~h}$.

9. After dehydration add $75 \mathrm{uL}$ per coverslip of warm hybridisation mix, cover plate and wrap in tissue soaked in hybridisation humidity buffer (see Note 13).

10. Put plates into hybridisation oven at chosen temperature for 12-16 hours.

11. Remove one plate from the oven, add $200 \mu \mathrm{l} \times 5$ SSC re-cover and replace in oven for 5 minutes, repeat with other plate. (see Note 14)

12. Remove plate(s) from oven and aspirate off SSC, replace with $200 \mathrm{uL} \times 0.2$ SSC and leave on bench for $1 \mathrm{~h}$ (see Note 15).

13. At this stage coverslips can be removed from dish and mounted on a slide for imaging as described in (3.5.17), however FAM labelled probes are prone to rapid photobleaching under a confocal microscope and it is advantageous to perform double immunocytochemistry and in-situ additional steps to label the hybridised mRNA with a more photo-stable fluorescent conjugated secondary antibody and simultaneous labelling of other proteins of interest..

7. Double immunocytochemistry and in situ hybridisation

1. To coverslips that have reached stage 12 of in-situ protocol (3.6.12) remove $\mathrm{x} 0.2 \mathrm{SSC}$ from crypts and place in post-hybridisation blocking solution for 90 minutes. During the blocking time prepare the anti-FAM primary antibody by pre-absorbing it in normal human serum $(10 \mu \mathrm{l}$ serum per $1 \mu \mathrm{l}$ antibody $)$ at room temperature for 1 hour and $37^{\circ} \mathrm{C}$ (waterbath) for 30 minutes (see Note 16). 
2. Allow pre-absorbed primary antibody mix to cool, add other primary antibodies (if required) and make up volume with TBS and $2 \%$ normal donkey serum to desired final concentration (see Note 17).

3. Aspirate off block and add $20 \mu 1$ of antibody/serum/TBS cocktail to each coverslip. Wrap (3.5.12) and leave for 20-24h at room temperature.

4. Add $200 \mu \mathrm{l}$ TBS to each coverslip, aspirate off. Repeat wash. Add secondary antibody made up in TBS. Protect from light and incubate for $2 \mathrm{~h}$ at room temperature. Repeat TBS wash and leave in TBS for 1h. Mount up coverslips (3.5.17) and image with a confocal microscope (see Fig. 6).

8. Cross-validation with immediately fixed microdissected (MD) crypts

1. A hydrophobic barrier pen is used to draw a rectangle about $1 \mathrm{~cm}$ by $2 \mathrm{~cm}$ on a plain glass slide and filled with dissection solution with so that a flattened dome forms (200-400 $\mu 1)$. The coverslip is positioned on a stage under a dissecting microscope (see Note 19)

2. A $1 \mathrm{~mm}$ square section of the fixed tissue is cut under the microscope and is then reduced to individual, intact, epithelial crypts by teasing them apart from the underlaying fibroblasts using a pair of micro dissecting knives.

3. When 5-10 individual crypts have been teased off it is advantageous to remove them from the coverslip for safe-keeping using $1 \mathrm{ml}$ pipette tip to aspirate them. Transfer to a $7 \mathrm{ml}$ bijoux on ice. The dome of dissection solution is replenished, and more individual crypts teased from the biopsy.

4. Repeat until at least 200 crypts have been obtained.

5. Dissected crypts are permeabalised for $1 \mathrm{~h}$ in a $0.5 \%$ solution of TritonX (Roche) in PBS at $4^{\circ} \mathrm{C}$ and then washed by replacing the solution with PBS twice. 
6. About 100 of the Individual crypts should be picked up using a $200 \mu 1$ pipette and placed into a $100 \mu 1$ aliquot of Matrigel that has been thawed on ice (see Note 20).

7. A $10 \mu 1$ drop of Matrigel is placed on each coverslip (in a 12 well culture dish) and put for 30 minutes in $37^{\circ} \mathrm{C}$ incubator to set the Matrigel. (see Note 21)

\section{Notes}

1. Obtain ethical approval and informed consent for collection of mucosal tissue samples from colorectal surgery or from recto/sigmoid endoscopy for research purposes.

2. The crypt isolation solution is devoid of calcium and magnesium which will serve to disaggregate the extracellular matrix proteins that secure the crypts in the lamina propria.

3. The vigour with which mucosal tissue samples are shaken at the end of the incubation period for isolation needs to be optimised in an empirical fashion so as to liberate single intact crypts or small groups of intact crypts that are not fragmented.

4. Crypt liberation will depend on the efficiency with which the calcium-/magnesiumfree crypt isolation solution causes (i) disaggregation of the extracellular proteins of the lamina propia, within which the crypts are embedded, and (ii) DTT-mediated lysis of extracellular mucus, which can form a barrier between the tissue samples and the crypt isolation solution. The incubation time in the crypt isolation solution may need to be extended if the crypts are slow to liberate.

5. $0.1 \%$ BSA contained within the crypt isolation solution (2.1.2) increases the specific gravity such that liberated crypts sediment to the bottom of Universal plastic bottles 
under gravity, whereas single contaminating mesenchymal cells such as myofibroblasts and lymphocytes do not.

6. Centrifugation is not recommended as it increases the likelihood of disrupting the integrity of liberated intact whole colonic crypts.

7. As pointed out previously[12], crypt viability is compromised by prolonged exposure to EDTA

8. Filling of peripheral wells with PBS and in-filling between wells with PBS will help prevent evaporation of culture medium

9. Crypt viability can be maintained for up to one month, but there is an increasing propensity for organoid formation[13]

10. Plastic dishes/lids interfere with DIC optics

11. Design and synthesise oligonucleotide probes with at least two 5/6carboxyfluorescein succinimidyl ester (5/6FAM) molecules at 5'and 3' ends for the target mRNA (This protocol was developed using Exiqon Custom LNTM detection probes with 20mer sequence flanked by 5/6FAM molecules at 5' and 3' ends).

Scrambled probes should be used as a negative control. A positive control probe for a ubiquitously expressed gene such as beta actin should also be used[18].

12. Calculate and ensure enough reagents are available for protocol, some reagents are best made shortly before using so whilst crypts are fixing, prepare reagents for next steps in protocol e.g. Proteinase K, denatured Salmon sperm DNA (SS DNA Sigma D7656) and add $2 \mu \mathrm{l}$ probe (probe concentration in range $10-75 \mathrm{nM}$ ) to $1433 \mu \mathrm{l}$ hybridisation buffer and $75 \mu \mathrm{l}$ SS DNA in $1.7 \mathrm{ml}$ flip top centrifuge tube and place mix in hybridisation oven to warm (approx $90 \mathrm{~min}$ ) to make hybridisation mix. PBS$\mathrm{MeOH}$ is also best used freshly prepared. 
13. Once the hybridisation mix has been added it is vital now that the coverslips never dry out again, so carefully wrap plate in an absorbent cloth soaked in formamide/x4 SSC solution and then over-wrapped with plastic film such as catering cling-film. Place in hybridisation oven (at temperature depending on probe but in range $40-70^{\circ} \mathrm{C}$ ) for at least $12 \mathrm{~h}$ (up to $16 \mathrm{~h}$ determined by experiment).

14. Remove one plate at a time from the oven, unwrap but do not discard) and add $200 \mu 1$ of $\mathrm{x} 5 \mathrm{SSC}$ to each coverslip (there will not be sufficient probe remaining to aspirate), wrap up to prevent dessication and return to the oven (bottom shelf) for 5 minutes.

15. Remove from oven, remove and discard wrapping, aspirate off x5 SSC and replace with sufficient $\mathrm{x} 0.2 \mathrm{SSC}$ to cover crypts and leave for 1 hour at room temperature. If double immunocytochemistry and in-situ is attempted then the following steps in protocol prepare the hybridised crypts for the addition of primary antibodies.

16. It is essential that no phosphate containing buffers are used from here as it may interfere with the hybridised probe, only use TBS .

17. The addition of $2 \%$ donkey serum to block is to reduce non-specific binding when donkey fluorescence conjugated secondary antibodies are used (or substitute relevant secondary antibody species).

18. If MD crypts are to be used for in-situ hybridisation then all solutions must be made with DEPC treated water, and particular attention paid to cleaning instruments and surfaces to avoid dnase contamination

19. Twin spot light sources of the dissecting microscope should be adjusted so that a near horizontal beam of light falls on the specimen from either side. Correct positioning of the light source aids depth perception of the specimen when dissecting.

20. The minimum amount of fluid should be taken up with the crypts to avoid excessive dilution of the Matrigel. Gravity sedimentation of crypts is preferable to pelleting by 
centrifugation as the latter can cause clumping of the dissected and permeabalised crypts when resuspending in Matrigel.

21. When the Matrigel has set crypts can be covered with $200 \mu 1$ per well of PBS and stored at $37^{\circ} \mathrm{C}$ for 1 day, or fixed in PFA for immediate processing for Immunocytochemistry or in-situ hybridisation

\section{Acknowledgements}

We are grateful to all past and present members of the Williams laboratory for their input into the development and application of the human colonic crypt culture system. Work in the Williams laboratory has been funded by grants from the Biotechnology and Biological Sciences (BB/F015690/1, BB/D018196/1), the Humane Research Trust, Big C cancer charity, John and Pamela Salter Charitable Trust.

1. Sato T, Clevers H (2013) Growing self-organizing mini-guts from a single intestinal stem cell: mechanism and applications. Science 340 (6137):1190-1194. doi:10.1126/science.1234852 2. Vermeulen L, Morrissey E, van der Heijden M, Nicholson AM, Sottoriva A, Buczacki S, Kemp R, Tavare S, Winton DJ (2013) Defining stem cell dynamics in models of intestinal tumor initiation. Science 342 (6161):995-998. doi:10.1126/science.1243148

3. Whitehead RH, Brown A, Bhathal PS (1987) A method for the isolation and culture of human colonic crypts in collagen gels. In vitro cellular \& developmental biology : journal of the Tissue Culture Association 23 (6):436-442

4. Gibson PR, van de Pol E, Maxwell LE, Gabriel A, Doe WF (1989) Isolation of colonic crypts that maintain structural and metabolic viability in vitro. Gastroenterology 96 (2 Pt 1):283-291

5. Grossmann J, Maxson JM, Whitacre CM, Orosz DE, Berger NA, Fiocchi C, Levine AD (1998) New isolation technique to study apoptosis in human intestinal epithelial cells. The American journal of pathology 153 (1):53-62. doi:10.1016/s0002-9440(10)65545-9

6. Strater J, Wedding U, Barth TF, Koretz K, Elsing C, Moller P (1996) Rapid onset of apoptosis in vitro follows disruption of beta 1-integrin/matrix interactions in human colonic crypt cells.

Gastroenterology 110 (6):1776-1784

7. Reynolds A, Parris A, Evans LA, Lindqvist S, Sharp P, Lewis M, Tighe R, Williams MR (2007) Dynamic and differential regulation of NKCC1 by calcium and CAMP in the native human colonic epithelium. $J$ Physiol 582 (Pt 2):507-524. doi:10.1113/jphysiol.2007.129718

8. Batlle E, Henderson JT, Beghtel H, van den Born MM, Sancho E, Huls G, Meeldijk J, Robertson J, van de Wetering M, Pawson T, Clevers $\mathrm{H}$ (2002) Beta-catenin and TCF mediate cell positioning in the intestinal epithelium by controlling the expression of EphB/ephrinB. Cell 111 (2):251-263. doi:S0092867402010152 [pii]

9. van de Wetering $M$, Sancho E, Verweij C, de Lau W, Oving I, Hurlstone A, van der Horn K, Batlle E, Coudreuse D, Haramis AP, Tjon-Pon-Fong M, Moerer P, van den Born M, Soete G, Pals S, Eilers $M$, Medema R, Clevers H (2002) The beta-catenin/TCF-4 complex imposes a crypt progenitor phenotype on colorectal cancer cells. Cell 111 (2):241-250. doi:S0092867402010140 [pii] 
10. Barker N, van Es JH, Kuipers J, Kujala P, van den Born M, Cozijnsen M, Haegebarth A, Korving J, Begthel H, Peters PJ, Clevers H (2007) Identification of stem cells in small intestine and colon by marker gene Lgr5. Nature 449 (7165):1003-1007. doi:nature06196 [pii]

10.1038/nature06196

11. Sato T, Vries RG, Snippert HJ, van de Wetering M, Barker N, Stange DE, van Es JH, Abo A, Kujala P, Peters PJ, Clevers H (2009) Single Lgr5 stem cells build crypt-villus structures in vitro without a mesenchymal niche. Nature 459 (7244):262-265. doi:nature07935 [pii] $10.1038 /$ nature07935

12. Sato T, Clevers H (2013) Primary mouse small intestinal epithelial cell cultures. Methods in molecular biology (Clifton, NJ) 945:319-328. doi:10.1007/978-1-62703-125-7_19

13. Sato T, Stange DE, Ferrante M, Vries RG, Van Es JH, Van den Brink S, Van Houdt WJ, Pronk A, Van Gorp J, Siersema PD, Clevers H (2011) Long-term expansion of epithelial organoids from human colon, adenoma, adenocarcinoma, and Barrett's epithelium. Gastroenterology 141 (5):1762-1772. doi:S0016-5085(11)01108-5 [pii]

10.1053/j.gastro.2011.07.050

14. Jung P, Sato T, Merlos-Suarez A, Barriga FM, Iglesias M, Rossell D, Auer H, Gallardo M, Blasco MA, Sancho E, Clevers H, Batlle E (2011) Isolation and in vitro expansion of human colonic stem cells. Nat Med 17 (10):1225-1227. doi:10.1038/nm.2470

15. Spence JR, Mayhew CN, Rankin SA, Kuhar MF, Vallance JE, Tolle K, Hoskins EE, Kalinichenko VV, Wells SI, Zorn AM, Shroyer NF, Wells JM (2011) Directed differentiation of human pluripotent stem cells into intestinal tissue in vitro. Nature 470 (7332):105-109. doi:10.1038/nature09691

16. Watson CL, Mahe MM, Munera J, Howell JC, Sundaram N, Poling HM, Schweitzer JI, Vallance JE, Mayhew CN, Sun Y, Grabowski G, Finkbeiner SR, Spence JR, Shroyer NF, Wells JM, Helmrath MA (2014) An in vivo model of human small intestine using pluripotent stem cells. Nat Med 20 (11):1310-1314. doi:10.1038/nm.3737

17. Yui S, Nakamura T, Sato T, Nemoto Y, Mizutani T, Zheng X, Ichinose S, Nagaishi T, Okamoto R, Tsuchiya $\mathrm{K}$, Clevers $\mathrm{H}$, Watanabe $\mathrm{M}$ (2012) Functional engraftment of colon epithelium expanded in vitro from a single adult Lgr5(+) stem cell. Nat Med 18 (4):618-623. doi:nm.2695 [pii]

10.1038/nm.2695

18. Reynolds A, Wharton N, Parris A, Mitchell E, Sobolewski A, Kam C, Bigwood L, El Hadi A, Munsterberg A, Lewis M, Speakman C, Stebbings W, Wharton R, Sargen K, Tighe R, Jamieson C, Hernon J, Kapur S, Oue N, Yasui W, Williams MR (2014) Canonical Wnt signals combined with suppressed TGFbeta/BMP pathways promote renewal of the native human colonic epithelium. Gut 63 (4):610-621. doi:10.1136/gutjnl-2012-304067

19. Kosinski C, Li VS, Chan AS, Zhang J, Ho C, Tsui WY, Chan TL, Mifflin RC, Powell DW, Yuen ST, Leung SY, Chen X (2007) Gene expression patterns of human colon tops and basal crypts and BMP antagonists as intestinal stem cell niche factors. Proc Natl Acad Sci U S A 104 (39):15418-15423. doi:0707210104 [pii] 10.1073/pnas.0707210104

\section{Figure legends}

Figure 1: Hierarchy of stem cell-driven renewal of the human colonic epithelium. The human colonic crypt base contains a mixture of proliferating stem cells, mitotic progenitor cells, and post-mitotic differentiated cells. Cells in the upper half of the crypt are mostly post-mitotic and migrate in an upward direction to the surface epithelium . On reaching this 
destination they are shed into the crypt lumen . These cells are replaced by stem cell progeny that emanate from the stem cell niche and differentiate en route to the surface epithelium.

Figure 2: Human colonic crypt culture. (a) \& (b) A typical field of view for human colonic crypts following 7 days in culture. Open arrowheads indicate crypt bases and filled arrowheads indicate accumulation of shed cells at the crypt opening. (c) higher magnification view of crypts over 4 days and 7 days of culture. (Adapted from Ref. 18)

Figure 3: Real-time imaging of crypt cell division. DIC imaging of cell nucleus migration from the basal pole to the apical pole $(20 \mathrm{~min}$.) followed by cytokinesis $(35 \mathrm{~min}$.) and return of daughter cell nuclei to the basal pole (75 min.).

Figure 4: Hierarchy of calcein-labelled live cells and propidium iodide (PI)-positive dead cells. The number of PI-positive shed cells increases over time in culture. (Adapted from Ref. 18)

Figure 5: Live cell imaging of calcium signalling along the colonic crypt-axis. Fura2 loaded crypts were stimulated with acetylcholine $(10 \mu \mathrm{M})$. The F340/F380 pseudocolour ratio images demonstrate that acetylcholine induces a calcium signal in the stem cell niche which propagates along the crypt-axis with respect to time. (Adapted from Ref. 7)

Figure 6: Labelling human intestinal stem/progenitor cells. Stem cell markers LGR5 and OLFM4 were labelled in native human colonic crypts micro-dissected from a fixed biopsy specimen. Microdissected crypts were subjected to either immunocytochemistry for LGR5 (Origene mouse monoclonal antibody clone 2A2) and OLFM4 (Abcam rabbit polyclonal 
antibody) or double LGR5 mRNA in situ hybridisation and OLFM4 immunocytochemistry. Similar observations were made for cultured crypts[18]. 


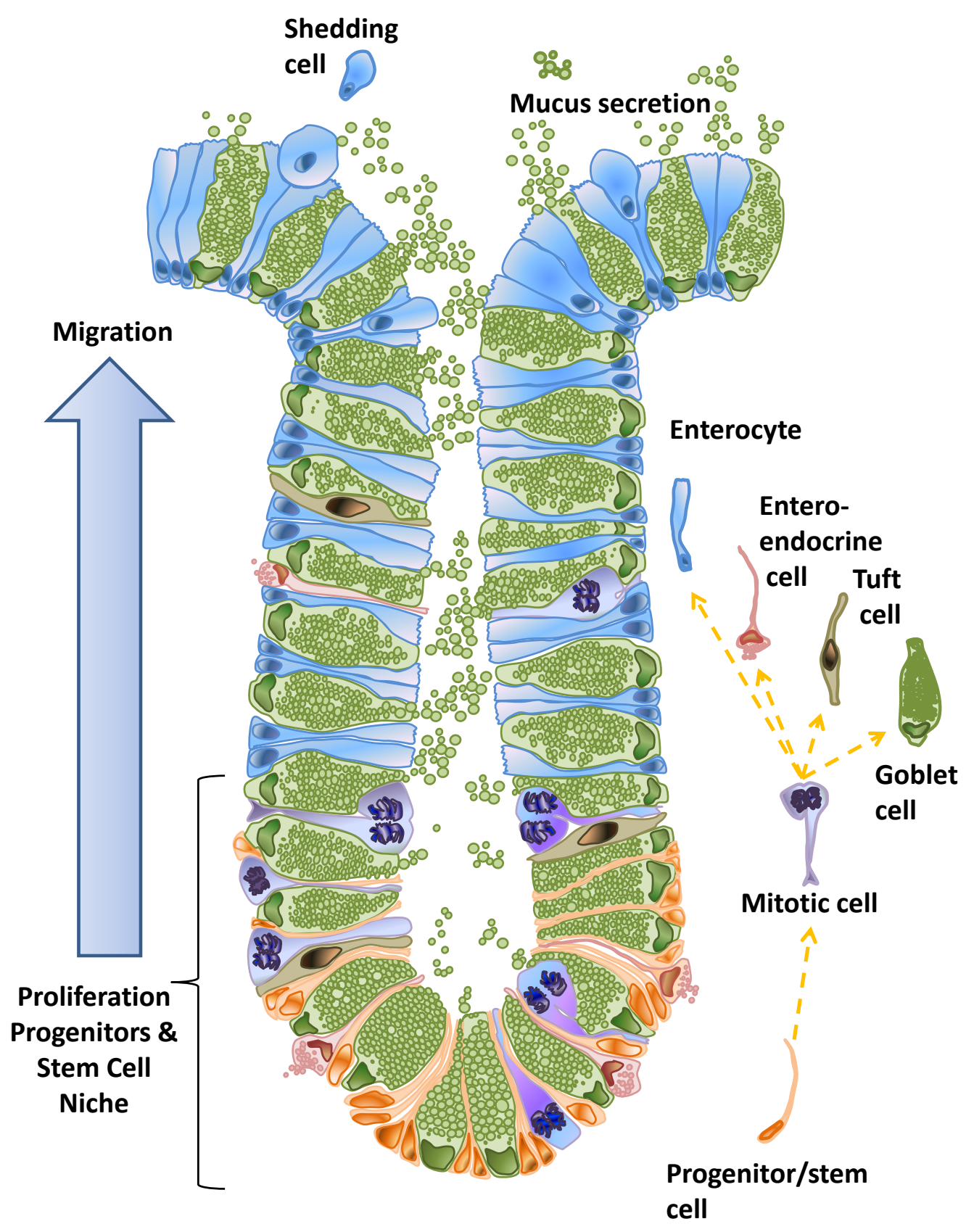

Figure 1 

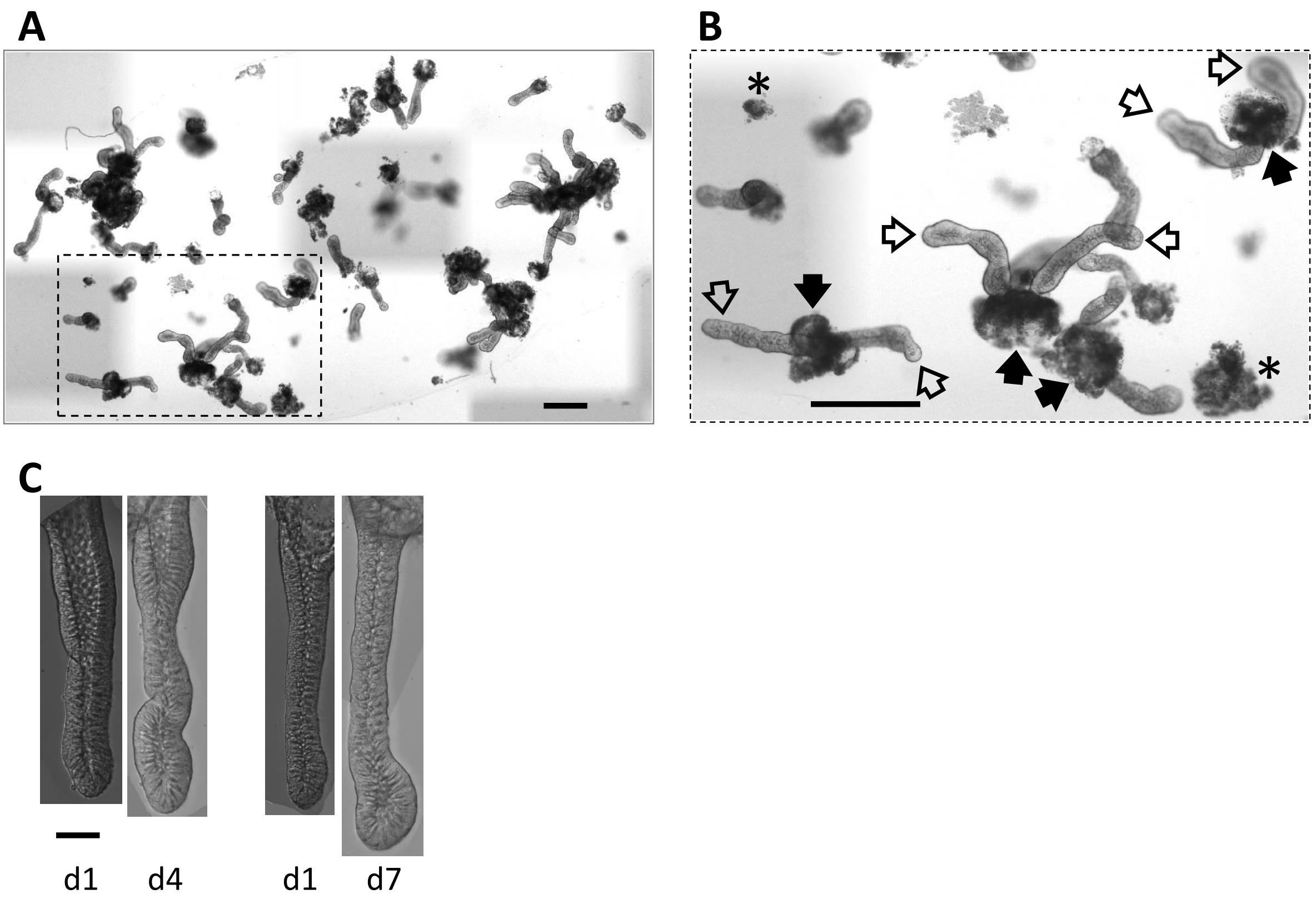

Figure 2 

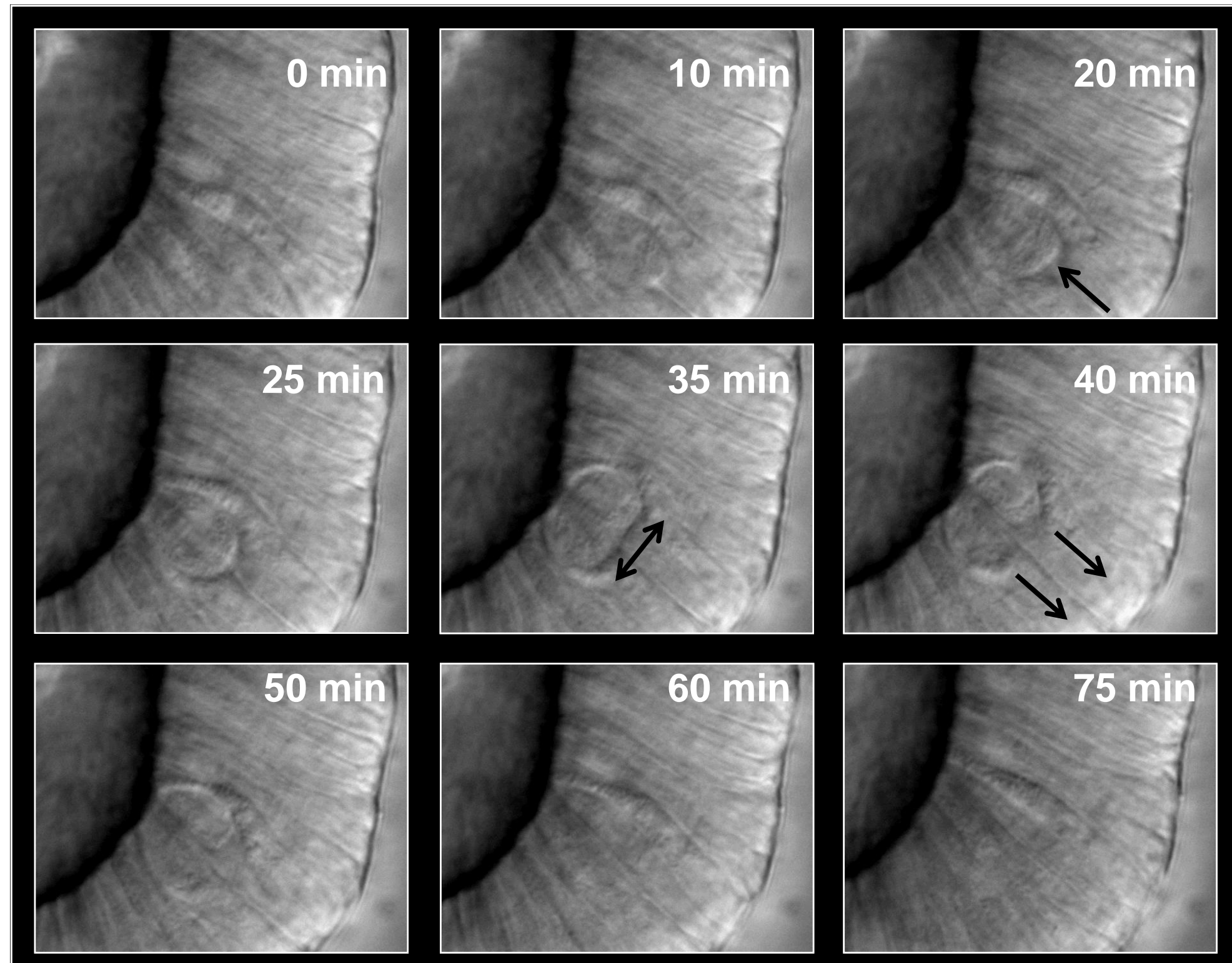

Figure 3 

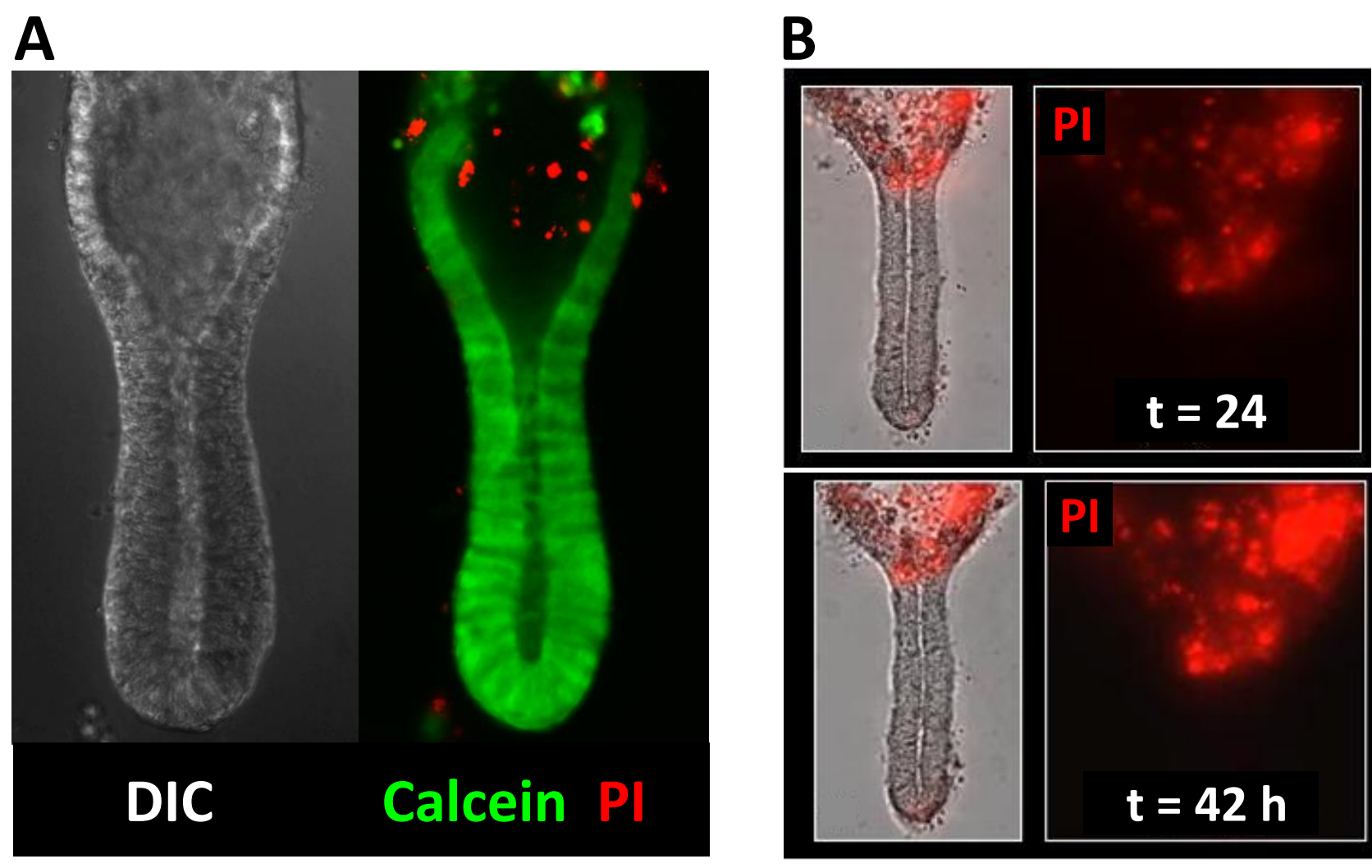

Figure 4 

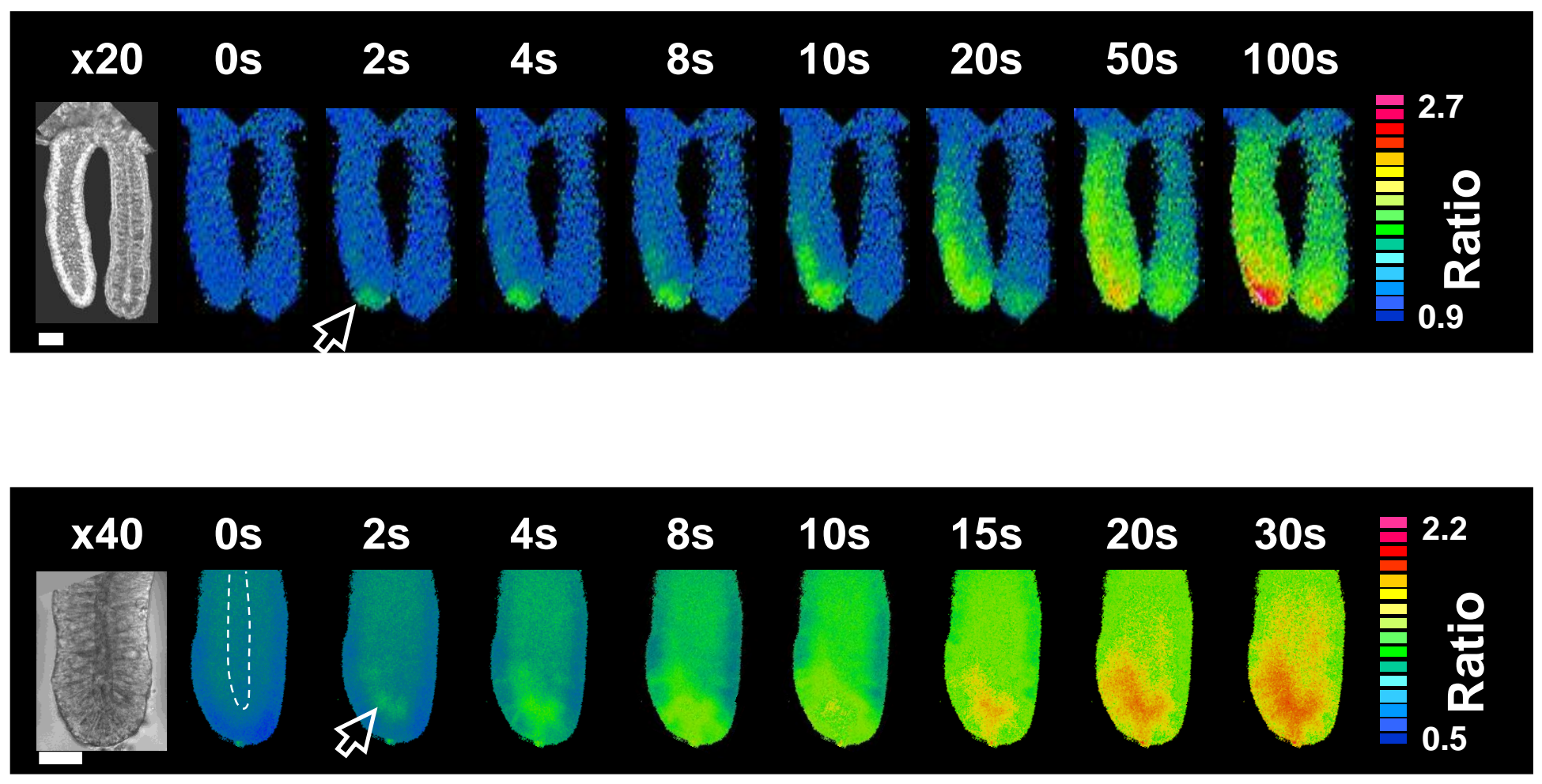

Figure 5 

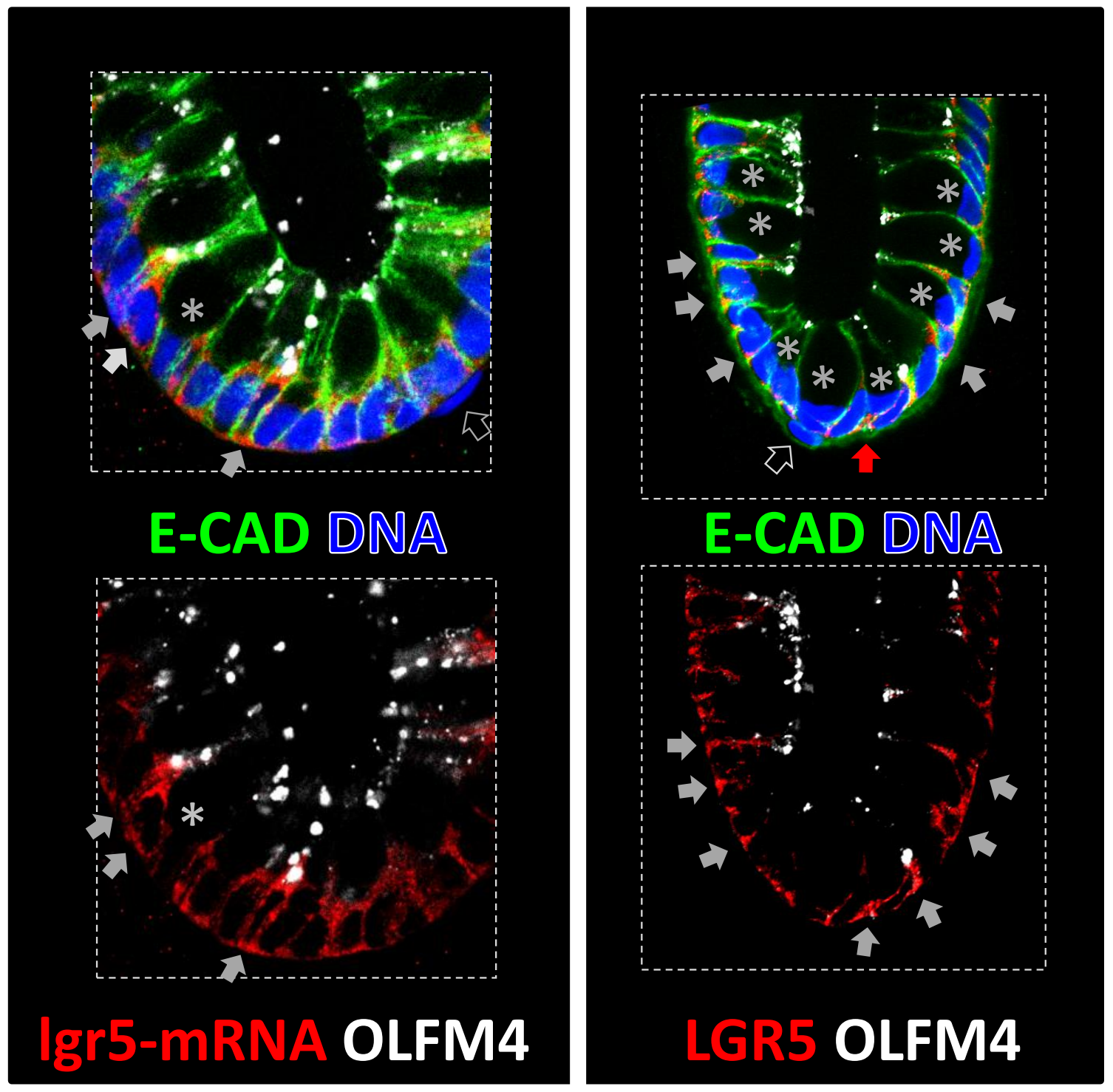

Figure 6 